\title{
PUBLIC AWARENESS AND PERCEPTIONS OF ORGAN DONATION IN BULGARIA AND ACROSS THE EUROPEAN UNION
}

\author{
Kerekovska A. \\ Department of Social Medicine and Health Care Organisation, \\ Medical University of Varna
}

Reviewed by: assoc. prof. St. Popova

\begin{abstract}
The aim of this study is to describe comparatively public awareness, attitudes and perceptions of organ donation and transplantation among Bulgarian and the European population, and to identify those practices and actions that can have positive impacts for Bulgaria. The methods involve extensive content review of EU documentation and comparative data analysis of international publications containing figures on organ donation. Main source of information is representative data drawn from the Eurobarometer cross-national survey on organ donation. The comparative $\mathrm{EU}$ data on public awareness, attitudes and perception of organ donation reveals large variations by country. Compared to the majority of the European population, the Bulgarian respondents express less supportive attitudes and less positive perceptions. Bulgarians are far less likely than the Europeans as a whole to agree to the donation of an organ from a deceased family member and to consent to own organs donation after death. They have substantially lower rates of family discussions about organ donation. The awareness of Bulgarian population of transplantation legal regulations is among the lowest in Europe. The results point to the need for Bulgaria to strengthen its international cooperation and exchange good practices with EU member states. It is important to establish effective communication to count on all the social actors included in the transplantation process. Efforts to encourage family discussions on organ donation; to educate health professionals, media and the public; and to build their confidence in the health system and the transplantation service would be of high potential for the country. These actions are all essential for future positive developments in organ donation and transplantation in Bulgaria.
\end{abstract}

Key words: organ donation, public awareness and perceptions, Bulgaria, European Union

\section{INTRODUCTION}

The number of organ donations and transplantations has grown steadily across the EU. However, the level of organ donation does not come close to meeting the demand, and nearly 10 people die every day in Europe while waiting for an organ (6). The severe shortage of organ donors remains the main challenge that the EU faces with regard to organ transplantation. Though a universal problem for all Member States, there are wide variations across the EU on organ donation rates, ranging from 34.6 donations per million people in Spain to 0.5 in Romania $(1,5)$. It is difficult to attribute these huge differences between Member States to one single factor, but several reasons have been identified, such as a mix of cultural, historical and social factors combined with characteristics of the health service and the or-

Address for correspondence:

Al. Kerekovska, Dept. of Social Medicine and Health Care Organisation, Faculty of Public Health, Medical University of Varna

55 Marin Drinov St., Varna 9002, Bulgaria

e-mail:kerekovska_a@yahoo.com ganisational and legal aspects of the donation system within a country $(6,9)$. The level of public awareness of organ donation and its legal regulations is a key factor influencing the transplantation activity of each country $(7,8)$. There is also ample evidence showing that supportive public attitudes and positive perceptions could lead to substantial increases in organ donation rates (9).

Bulgaria's record of transplantation activity is one of the lowest in Europe - with organ donation rates of 1.5 per million population (1). Studying comparatively the Bulgarian experience and the heterogeneity of public attitudes and perceptions within Europe will contribute to the identification of valuable actions that can positively impact on the Bulgarian situation of organ donation. There is scope for cooperation between EU countries and sharing of good practices can help increase public support of organ donation and improve transplantation rates in Bulgaria.

The aim of this study is to describe comparatively public awareness, attitudes and perceptions of organ donation and transplantation among Bulgarian and the European population, and to identify those practices and actions that can have positive impacts for Bulgaria. 


\section{MATERIAL AND METHODS}

The methods involve extensive content review of EU documentation and comparative data analysis of international publications containing figures on organ donation. Main source of information is the representative data of the European Commission drawn from the Eurobarometer cross-national surveys on organ donation undertaken in 2006 and 2009 with respondents throughout the EU.

\section{RESULTS}

\section{Family Discussions}

$40 \%$ of Europeans have raised the issue of organ donation and transplantation with their family, compared to $59 \%$ who have never broached this subject. The analysis by country reveals a huge disparity between results for the oldest EU Member States and the most recent ones, with the latter generally recording lower rates of family discussion. Countries with highest family discussion rates are the Netherlands (74\%), Sweden (62\%) and Denmark (58\%). The lowest levels of discussion are recorded among respondents in Latvia, Estonia and the Czech Republic (15\%, 17\% and 18\% respectively) (3). The data on Bulgarian population also reveals rates among the lowest in the EU. Only $22 \%$ of the Bulgarian respondents (4) have discussed the issue of human organ donation and transplantation with their family (Table 1).

Table 1. Attitudes to organ donation and level of legislation awareness: Comparative data on the $E U$ and Bulgaria, 2009.

\begin{tabular}{||l|c|c|c||}
\hline $\begin{array}{l}\text { Attitudes to organ donation } \\
\text { and level of legislation } \\
\text { awareness }\end{array}$ & EU27 & Bulgaria & $\begin{array}{c}\text { Difference } \\
\text { from EU } \\
\text { average }\end{array}$ \\
\hline $\begin{array}{l}\text { Has already discussed } \\
\text { donation of organs \% Yes }\end{array}$ & $40 \%$ & $\mathbf{2 2 \%}$ & $-18 \%$ \\
\hline $\begin{array}{l}\text { Aware of legal regulations on } \\
\text { organ donation \% Yes }\end{array}$ & $28 \%$ & $\mathbf{1 5 \%}$ & $-13 \%$ \\
\hline $\begin{array}{l}\text { Willing to donate his/her own } \\
\text { organ after death \% Yes }\end{array}$ & $55 \%$ & $\mathbf{4 2 \%}$ & $-13 \%$ \\
\hline $\begin{array}{l}\text { Would agree to donate an } \\
\text { organ of a deceased close } \\
\text { family member \% Yes }\end{array}$ & $53 \%$ & $\mathbf{4 4 \%}$ & $-9 \%$ \\
\hline \hline
\end{tabular}

\section{Awareness about Regulation of Organ Donation and Transplantation}

Only $28 \%$ of the Europeans are aware of laws governing the donation and transplantation of organs in their country. By contrast, $68 \%$ of people do not know such laws (3). The analysis of results reveals significant differences by country, with a general pattern of higher awareness levels in the oldest European Union Member States and lower levels in the most recent ones. The highest awareness level of laws relating to organ donation is noted in the Netherlands (64\%), followed by Denmark (45\%).
Most other countries which joined the European Union before 2004 record awareness levels in the $20 \%$ to $40 \%$ range. The lowest awareness levels in the EU are noted in the Czech Republic and Estonia (10\% and $8 \%$ respectively), followed by Latvia and Bulgaria - both $15 \%$. (Table 1). There is a strong association between family discussion and knowledge of laws. Of those in the EU who have discussed organ donation and transplantation with their family, nearly half (48\%) say they know the laws governing this area in their country. For Bulgaria, this proportion is substantially lower $-33 \%(3,4)$.

\section{Donating One's Own Organs}

The majority of the Europeans (55\%) are willing to donate their own organs after their death. Just over one in four is against the idea $(27 \%)$, while almost one in five felt unable to express an opinion on the topic (18\%). An analysis of results by country reveals some significant differences. Populations of the Northern European countries show a higher willingness to donate their own organs. The strongest support is noted in Sweden (83\%); high levels are recorded in Finland and Belgium (both $72 \%$ ), and Denmark (70\%). At the other end of the scale, those most reluctant to donate their own organs tend to reside in Eastern European countries, especially Latvia and Romania, where only $25 \%$ and $31 \%$ of population respectively is willing to donate own organs after death (3).

Bulgaria also records one of the lowest support for own organs donation - just only $42 \%$ would be willing to donate their own organs and $27 \%$ are firmly against (4) (Table 1). In the overall wide variation by country in the proportion of individuals who were not sure if they would be willing to donate, the greatest uncertainty and indecisiveness is recorded for Bulgaria, with $31 \%$ of the respondents unable to express opinion on the issue.

\section{Donating an Organ from a Deceased Close Family Member}

Over half of Europeans (53\%) would agree to donate an organ from a deceased close family member if asked in a hospital (3). Considerable differences are apparent by country in the hypothetical willingness to donate a family member's organs. Not surprisingly, the countries with the highest levels of consent for donation of the organs of a deceased relative are the same countries where high levels of consent for donation of one's own organ are noted. Sweden (73\%), Finland (72\%), Malta (72\%) and Belgium (68\%) remain the countries with highest consent levels. The lowest levels of acceptance are noted in Romania (34\%), Austria (35\%) and Latvia (36\%) (3). The rates for Bulgaria (44\%) (Table 1), though not the lowest in the EU, are again substantially lower than the European average. A total of $27 \%$ said they would refuse to donate a deceased relative's organs (4). Moreover, when not the hypothetical willingness but the real situation is considered, Bulgaria proves to be the EU country with the highest rates of actual family refusals for deceased organ donation. In Bulgaria, $80 \%$ of relatives of individuals with brain death refuse to donate their organs, compared to $10 \%$ and $15 \%$ respectively for Portugal and Spain (2). 
Overall, respondents are much more likely to be unsure about consenting to the donation of an organ from a deceased relative. For the EU as a whole, $22 \%$ of the population responded "Don't Know" when asked if they would consent to the donation of a deceased relative. The Bulgarian population again shows the highest indecisiveness and greatest uncertainty - with $34 \%$ of the respondents not able to express a certain opinion about willingness to donate close family's organs (4).

\section{Reasons for Not Donating Organs}

On average, distrust of the system and fear of manipulation of the human body are the dominant reasons for not donating one's own organs or those of a deceased close family member in the EU countries. Almost a third of Europeans (31\%) who are unwilling to donate either their own organs or those of a deceased relative are unable to give a reason for their reluctance. Of the remainder, a quarter (25\%) are fearful of manipulation of the human body, and one in five (21\%) cite distrust of the system (either the transplantation system, consent system, and/or general health and social system) as a barrier to donation. Less than one in ten Europeans (7\%) do not support organ donation for religious reasons (3). Considering barriers to organ donation on a country level, significant differences are apparent, not necessarily related to region of European Union or number of years as a Member State. Distrust of the system is most prevalent as a barrier in Greece (45\%), the Czech Republic (33\%), Slovakia (31\%), Italy (30\%) and Bulgaria $(26 \%)$. Confusion and not certainty about reasons for not donating organs is most prevalent in Malta $(76 \%)$, Ireland $(64 \%)$, Finland (53\%), Estonia (52\%) and the two newest Member States, Bulgaria and Romania (both 48\%) (3).

A fear of human body manipulation (19\%) and religious reasons (4\%) are donation barriers of low and insignificant prevalence in the Bulgarian population (4), substantially lower than the EU average rates (Figure 1).

\section{DISCUSSION}

The comparative EU data on public attitude and perception of organ donation and transplantation reveals very large variations by country of residence. The Bulgarian society as a whole still does not take a positive view of organ donations. Compared to the majority of the European population, the Bulgarian respondents express less supportive attitudes and less positive perceptions. Bulgarians are far less likely than the Europeans as a whole to agree to the donation of an organ from a deceased family member and to consent to own organs donation after death. They have substantially lower rates of family discussions about organ donation. Moreover, the knowledge of Bulgarian population on transplantation legal regulations is among the lowest in Europe.

The large variations in public awareness and perceptions of organ donation across the EU member states point to the potential of greater international cooperation in this field, including the exchange of good practices from countries which have been most successful in raising awareness and public education in this field. This could be of benefit to some of the newer Member States whose health systems

Figure 1. Reasons for not donating organs, Bulgaria and EU average

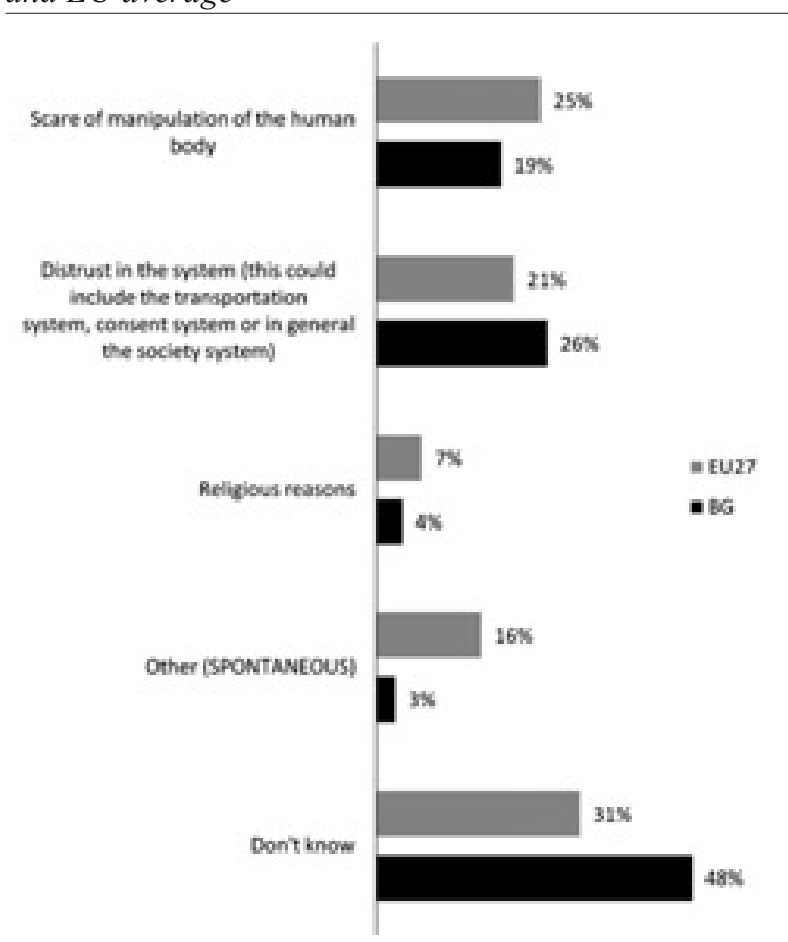

Source: Eurobarometer 72.3: Results for Bulgaria, 2010.

have fewer resources and are, therefore, under more pressure when it comes to transplantation. International cooperation could be of great value in particular to Bulgaria, whose organ donation rates and score of population support are among the lowest in the EU.

Family discussions on organ donation have been noted as positively correlated with the support for organ donation (9). Therefore, efforts to encourage more open family discussions on donation and communication of wishes to the relatives can contribute to positive evolution in Bulgaria. Knowledge about organ donation policy and legislation has also been found to increase individuals' willingness to donate their own organs and those of a relative $(6,9)$. Public education and awareness campaigns on organ donation and its legal regulation in Bulgaria could help to trigger this and change attitudes in a positive direction.

The Bulgarian population proves to be most indecisive in making decisions about willingness for donation of both own and relative's organs. It also seems to be the most confused and uncertain about the reasons for not willing to donate. These high rates of confusion, uncertainty and indecisiveness also call for greater investment in targeted communication and information provision, as well as systematic public education.

Distrust of the system (the healthcare, the transplantation system, consent system, and/or general social system) is also among the most dominant barriers to donation for the Bulgarian population. Therefore, building public confidence and credibility in the health system in general and the 
transplantation system in particular is a way to positively change public attitudes to donation and increase organ availability. Greater transparency, objectivity, equity, accountability and control would strengthen the credibility of the National Executive Transplant Agency and help Bulgarian citizens overcome their fears, distrust and skepticism against the reliability of the system.

Raising public involvement also has a role to play in increasing support for organ donation of the Bulgarian population. Organ donation and transplantation activities call for active participation of medical professionals, stakeholders, authorities and the general public: i.e., of society as a whole. Recognition of the innate complexity of the whole transplantation process and of the consequent need for active participation of all its actors is a basic step for further advancement of organ procurement rates in Bulgaria. Therefore, it is crucial to establish effective communication to count on all the social actors included in the process. Important target audience for the communication process should be the health professionals, the media, opinion leaders, patients support groups and the general public. Their continuing education should form an essential element of the communication strategy on organ donation and transplantation in Bulgaria.

\section{CONCLUSIONS}

Different EU societies have rather different attitudes towards organ donation. The Bulgarian society as a whole still does not take a positive view of organ donations. The reluctance of individuals to become organ donors or donate the organs of deceased relatives is a major factor impeding the transplant procedures in Bulgaria.

The low level of public awareness of organ donation and of the legal and ethical issues related to the field is a major barrier to more supportive perceptions of the Bulgarian population. The high degree of confusion and uncertainty in making decisions regarding organ donation is a main characteristic distinguishing Bulgarians from the majority of the EU populations. The public suspicion and distrust to the system remain a major challenge for improving public attitude towards organ donation in Bulgaria.

The comparative data analysis of public awareness and attitudes to organ donation points to the need for Bulgaria to strengthen its international cooperation and exchange good practices with EU member states. Efforts to encourage more open family discussions on organ donation; to edu- cate health professionals, the media and the public; and to build their confidence and credibility in the health system and the transplantation service would be of high potential for the country. It will also be important to pool efforts and expertise to establish effective communication to count on all the social actors included in the transplantation process. These actions are all essential for future positive developments in organ donation and transplantation in Bulgaria.

\section{REFERENCES}

1. Council of Europe. International Figures on Organ Donation and Transplantation Activity - Year 2008. Transplant Newsletter, 2009, 14(1): 27-29.

2. European Commission. Europeans and Organ donation. Report. Eurobarometer, 2007.

(http://ec.europa.eu/health/ph_threats/human_substance/documents/ebs272d_en.pdf).

3. European Commission. Eurobarometer Survey 72.3 on Organ Donation and Transplantation. Special Eurobarometer 333a, 2010. (http://ec.europa.eu/public_opinion/archives/ebs/ebs_333a_en.pdf).

4. European Commission. Eurobarometer Fact Sheets on Organ Donation and Transplantation. Results for Bulgaria, 2010. (http://ec.europa.eu/public_opinion/archives/ebs/ebs_333a_fact_bg_en.pdf).

5. European Commission. Key Facts and Figures on EU Organ Donation and Transplantation.

2009.(http://ec.europa.eu/health/ph_threats/human_substance/oc_organs/docs/fact_figures.pdf).

6. European Commission. Organ Donation and Transplantation: Policy Actions at EU Level. Communication from the Commission to the European Parliament and the Council. Brussels, 2007. (http://ec.europa.eu/health/ph_threats/human_substance/documents/organs_com_en.pdf).

7. Gross, T., Martinoli, S., Spagnoli, G., Badia, F. and Malacrida, R. Attitudes and Behavior of Young European Adults Towards the Donation of Organs - a Call for Better Information. American Journal of Transplantation, 2001, 1:74-81.

8. Mossialos, E., J. Font, C. Rudisill. Does Organ Donation Legislation Affect Individuals' Willingness to Donate their Own or Their Relative's Organs? Evidence from European Union survey data. BMC Health Services Research, 2008, 8:48.

9. RAND Europe. Improving Organ Donation and Transplantation in the European Union. Assessing the Impacts of European Action. Technical Report, 2008. (http://www.rand.org/content/dam/rand/pubs/technical_reports/2008/RAND_TR602.pdf). 